\title{
AVALIAÇÃO DO DESENVOLVIMENTO DE GENÓTIPOS DE FEIJOEIROS PARASITADOS POR MELOIDOGYNE INCOGNITA
}

\author{
PEIXOTO, Leonardo de Azevedo ${ }^{1}$ \\ BELAN, Leônidas Leoni ${ }^{2}$ \\ MORAES, Wanderson Bucker ${ }^{3}$ \\ ALVES, Fábio Ramos ${ }^{4}$ \\ FONSECA, Stênio Oggioni da ${ }^{5}$ \\ FONSECA, Abel Souza da ${ }^{6}$
}

\begin{abstract}
RESUMO: Este trabalho teve como objetivo avaliar o crescimento de genótipo de feijoeiros parasitados por Meloidogyne incognita em condições controladas. $\mathrm{O}$ experimento foi conduzido em delineamento inteiramente casualizado com oito repetições, disposto em arranjo fatorial $3 \times 4$, a saber: três genótipos de feijoeiro (Pérola, Córrego Alto e Amarelinho) e quatro níveis de inóculo de nematóide (0, 2.000, 4.000 e 6.000 nematóides.planta ${ }^{1}$ ). Foram avaliadas no final do ciclo da cultura as seguintes variáveis: número de folhas trifoliadas (NFT), diâmetro do caule (DC), área foliar ( $\mathrm{AF}$ ), número de galhas (NG), número de massas de ovos (NMO) e população final dos nematóides (PF). O genótipo Peróla apresentou maiores valores de MSF, MSC, MST e DC quando comparado ao Amarelinho. Contrariamente, o genótipo Amarelinho teve menor crescimento quando comparado com as demais cultivares. O número de galhas induzidas pelo nematóide no genótipo Pérola aumentou à medida que aumentou os níveis de inóculo. Houve tendência de aumento tanto do NMO quanto da PF à medida que foram aumentados os níveis de inóculo do nematóide. Os maiores valores de MSF e MST foram observados no genótipo Amarelinho com o aumento dos níveis de inóculo do nematóide.
\end{abstract}

Palavras chave: Phaseulus vulgaris. Nematóide das galhas. Sintomas causados. Resistência.

\section{EVALUATION OF THE GROWTH OF BEAN PLANTS GENOTYPES PARASITIZED BY MELOIDOGYNE INCOGNITA}

SUMMARY: This work had as objective to evaluate the growth of bean plants genotypes parasitized by Meloidogyne incognita under controlled conditions. The experiment was carried out on an entirely randomized design with eight replicates, disposed in a factorial arrangement $3 \times 4$, that are: three bean plants genotypes (Pérola, Córrego Alto e Amarelinho) and four levels of nematodes inoculum (0, 2.000, 4.000 e 6.000 nematodes.plant $\left.{ }^{-1}\right)$. At the end of the culture cycle the following variables were evaluated: number of trifoliate leaves (NFT), stem diameter (DC), leaf area (AF), number of galls (NG), number of egg masses (NMO) and final nematodes population (PF). The genotype Pérola presented higher values of MSF, MSC, MST and DC when compared to Amarelinho. Inversely, the genotype Amarelinho had lower movement when compared with the other cultivars. The number of galls induced by the nematode in the genotype Pérola increased as increased the inoculum levels. There was tendency of increase as much of NMO as of the PF as soon as the nematode inoculum levels were increased. The higher values of MSF and MST were observed on the genotype Amarelinho with the increase of the nematode inoculum levels.

\footnotetext{
${ }^{1}$ Bolsista de Iniciação Cientifica do Departamento de Produção Vegetal. Área: Melhoramento de plantas

${ }^{2}$ Engenheiro Agrônomo. Mestrando em Produção Vegetal pela Universidade Federal do Espírito Santo

${ }^{3}$ Acadêmico de Agronomia. Departamento de Produção Vegetal. Área Fitopatologia.

${ }^{4}$ Professor de Microbiologia do Departamento de Produção Vegetal. Área Fitopatologia.

${ }^{5}$ Engenheiro Agrônomo.

${ }^{6}$ Graduando de agronomia. Departamento de Engenharia Rural. Área Bioestatistica
} 
Keywords: Phaseulus vulgaris. Galls nematodes. Caused symtoms. Resistence.

\section{INTRODUÇÃO}

O feijoeiro comum (Phaseolus vulgaris L.) é a espécie mais cultivada entre as demais do gênero Phaseolus, sendo o Brasil o maior produtor mundial. Entretanto, a produção brasileira de feijão tem sido insuficiente para abastecer o mercado interno, devido a ocorrência de doenças, como os nematóides das galhas, Meloidogyne spp. (YOKOYAMA, 2003), principalmente Meloidogyne incognita comum em regiões com predominância de elevadas temperaturas e solos arenosos (PERRE ; SANTOS, 2002). De fato, o feijoeiro é considerado bom hospedeiro de $M$. incognita (BONETTI ; FERRAZ, 1981) e M. javanica (VIEIRA, 1993), e as perdas, devido ao ataque destes nematoides, podem chegar a 50-90\% (FREIRE ; FERRAZ, 1977; AGUDELO, 1980).

Bonetti e Ferraz (1981) mencionam várias medidas de manejo dos fitonematóides. Entretanto, de acordo com os autores, é de fundamental importância o conhecimento do momento adequado para implementá-las quando se pensa na aplicação integrada das táticas de controle. Segundo Campos (1999), o ideal é manipular a população do nematóide para mantê-la abaixo do limiar de dano econômico, definido como a intensidade de doença na qual o benefício do controle iguala-se ao seu custo. Entretanto, para que essa definição seja operacional e que o manejo integrado seja viável, é necessário quantificar os danos causados pelos fitonematóides. Vale ressaltar que o termo dano significa qualquer redução na quantidade ou qualidade da produção (VIEIRA, 1993).

Outra forma de manejo dos nematoides é a utilização de variedades resistentes. Fontes de resistência a Meloidogyne spp. já foram encontradas, porém são pouco exploradas (CARNEIRO et al., 1992; ROBERTS, 1992). Wander et al. (2003) encontraram genótipos resistentes ao Meloidogyne incógnita, podendo estes genótipos serem utilizados em programas de melhoramento.

De acordo com Michereff (2004), há muitos trabalhos sobre os danos causados por doenças foliares, mas poucos são aqueles que fazem alusão aos patógenos radiculares, entre eles os fitonematóides. Segundo o autor, deve-se determinar o impacto desses patógenos nas culturas que parasitam e para isso deve-se considerar não apenas a espécie do patógeno, mas também o quanto ele está presente na área.

Segundo Jesus Júnior et al. (2004), estimativas confiáveis dos danos causados pelos patógenos são um pré-requisito para o desenvolvimento de qualquer programa bem sucedido de controle de doenças, independentemente do método de manejo a ser empregado. 
No Brasil existe cultivares com resistência moderada aos nematoides, porém sem reduzir satisfatoriamente os danos causados por essa doença (MOURA ; REGIS, 1987; CARNEIRO et al., 1992; MOURA ; MOURA, 1994; PEDROSA et al., 2000)

Portanto, o objetivo do trabalho foi avaliar o crescimento de genótipo de feijoeiros parasitados por diferentes níveis de Meloidogyne incognita em condições controladas.

\section{MATERIAL E MÉTODOS}

O experimento foi realizado sob condições controladas no Centro de Ciências Agrárias da Universidade Federal do Espírito Santo-CCAUFES, Alegre-ES, localizado a uma altitude de $250 \mathrm{~m}$, latitude $=20^{\circ} 45^{\prime} \mathrm{S}$, longitude $=41^{\circ} 29^{\prime} \mathrm{WGr}$.

O esquema fatorial utilizado no experimento foi $3 \times 4$, sendo três genótipos de feijoeiro (Pérola, Córrego Alto e Amarelinho) e quatro níveis iniciais de inóculo de nematóide $\left(0,2.000,4.000\right.$ e 6.000 nematóides.planta $\left.^{-1}\right)$ em delineamento inteiramente casualisado com 8 repetições.

Os nematóides foram multiplicados e mantidos em raízes de tomateiro Lycopersicon esculentum Mill cultivar Santa Clara, em casa de vegetação, conforme descrito por Peixoto (1995). As sementes de feijão foram semeadas em vasos de $4 \mathrm{~L}$ de capacidade contendo substrato. O substrato empregado para o plantio do feijoeiro foi composto de solo e areia. $\mathrm{O}$ solo, colhido de local não cultivado, foi peneirado e autoclavado por 2 horas a $140^{\circ} \mathrm{C}$, sendo esse processo em três dias consecutivos, e depois foi misturado com a areia na proporção de 2:1 (solo e areia).

Foram semeadas duas sementes por sacola e, posteriormente, foi feito o desbaste deixando-se uma planta por vaso. A inoculação foi realizada 15 dias após a germinação das sementes de feijão. A extração dos ovos para a inoculação foi realizada seguindo a técnica proposta por Hussey e Barker (1973), modificada por Bonetti e Ferraz (1981), com trituração das raízes do tomateiro durante 30 segundos em liquidificador. As suspensões foram de 1000 ovos e/ou juvenis $\mathrm{ml}^{-1}$. A inoculação foi realizada por meio da deposição de uma suspensão, em dois orifícios no solo, na região próxima ao colo da planta a uma profundidade de 2 a $3 \mathrm{~cm}$.

A adubação foi realizada de acordo com Prezotti et al. (2007) mediante análise de solo. A irrigação foi realizada de maneira que a umidade do solo ficasse próximo da capacidade de campo.

Ao término do ciclo dos feijoeiros (quarenta dias após a inoculação), foram quantificados os danos que os nematóides causaram às plantas. Para isso, foram determinados 
o número de folhas trifolioladas (NFT), diâmetro do caule (DC) e área foliar (AF). O NFT foi obtido por contagem. O DC foi obtido com o auxilio de um paquímetro. A área foliar foi obtida utilizando a fórmula descrita por Bassanezi (1995).

$$
\mathrm{LA}=\Sigma\left(3,03 \mathrm{~L}^{1,87}\right) \text {, onde }
$$

L é a maior largura em $\mathrm{cm}$ do folíolo central de cada folha da planta de feijão e LA (área foliar) é dado em centímetros quadrado.

Posteriormente, a parte aérea das plantas foi cortada e colocada em estufa por 72 horas a $70^{\circ} \mathrm{C}$, e posteriormente foi realizado a pesagem das folhas e o caule para o cálculo da massa fresca das folhas (MSF) e da massa seca do caule (MSC), respectivamente. Com a soma da MSF e MSC foi obtido a massa seca total (MST). O sistema radicular foi lavado cuidadosamente, dentro de um balde plástico, e foi feita a contagem visual das galhas, para a quantificação do número de galhas $(\mathrm{NG})$ e posteriormente do número de massas de ovos (NMO) por sistema radicular. Para a avaliação do NMO, as raízes foram imersas em solução de floxina B para garantir uma melhor visualização das massas de ovos.

A população final dos nematóides $(\mathrm{PF})$ foi determinada empregando-se o método de Hussey e Barker (1973), modificado por Bonetti e Ferraz (1981).

Os dados foram submetidos à análise estatística utilizando-se o programa GENES versão Windows (CRUZ, 2006). Foram realizados teste de médias e regressões a $5 \%$ de probabilidade.

\section{RESULTADOS E DISCUSSÃO}

Houve diferença significativa entre os genótipos, porém não houve interação entre genótipos e população inicial de nematoides. O genótipo Pérola apresentou os maiores valores de MSF, MSC, MST e DC em relação aos demais (Tabela 1). O genótipo Córrego Alto apresentou maiores MST e DC comparado ao Amarelinho (Tabela 1). Portanto o genótipo Pérola, mesmo em altas infestações de nematoide, resiste mais ao parasitismo destes em relação aos demais genótipos, pois o número de galhas induzidas pelo nematóide nesse genótipo aumentou a medida que aumentou a infestação inicial (Figura 1), acontecendo o mesmo com o NMO e a PF (Figura 2 e 3). Trabalhos realizados por Simão et al. (2010) com onze genótipos de feijão demonstraram que o genótipo Pérola foi susceptível ao Meloidogyne javanica, onde foi obtido um fator de reprodução igual a 1,91 e NG de 70,1. 
Tabela 1. Matéria seca da folha (MSF), do caule (MSC), total (MST) e diâmetro do caule (DC) de três cultivares de feijoeiro (Pérola, Córrego alto e Amarelinho) parasitadas por Meloidogyne incógnita. Alegre-ES. 05 de maio de 2009.

\begin{tabular}{ccccc}
\hline & $\begin{array}{c}\text { Massa seca da } \\
\text { folha }(\mathbf{g})\end{array}$ & $\begin{array}{c}\text { Massa seca do } \\
\text { caule }(\mathbf{g})\end{array}$ & $\begin{array}{c}\text { Massa seca } \\
\text { total }(\mathbf{g})\end{array}$ & $\begin{array}{c}\text { Diâmetro do } \\
\text { caule }(\mathbf{c m})\end{array}$ \\
\hline Pérola & $0.664 \mathrm{a}^{*}$ & $0.377 \mathrm{a}$ & $1.061 \mathrm{a}$ & $0.29 \mathrm{a}$ \\
Córrego alto & $0.568 \mathrm{~b}$ & $0.259 \mathrm{a}$ & $0.889 \mathrm{ab}$ & $0.32 \mathrm{a}$ \\
Amarelinho & $0.359 \mathrm{~b}$ & $0.169 \mathrm{~b}$ & $0.486 \mathrm{~b}$ & 0.21 \\
\hline
\end{tabular}

* Médias seguidas pela mesma letra não diferiram estatisticamente pelo teste de tukey a 5\% de probabilidade.

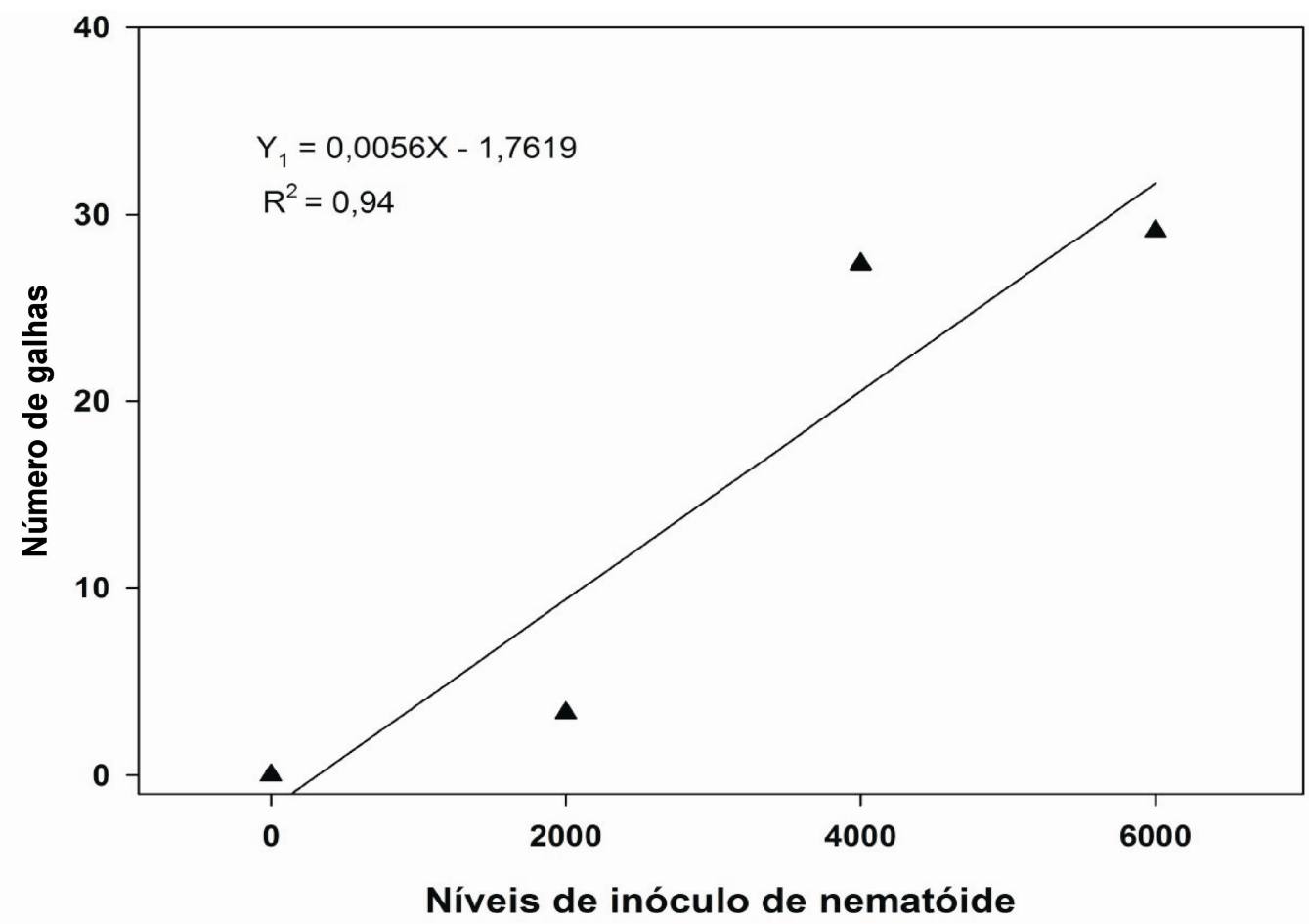

Figura 1. Número de galhas (NG) no feijoeiro Pérola parasitado por quatro níveis iniciais de inóculo de Meloidogyne incognita $(0 ; 2.000 ; 4.000$ ou 6.000 ovos + juvenis de segundo estádio (J2)/planta). Alegre-ES. 05 de maio de 2009.

Observou-se aumento do NMO e da PF para todos os genótipos (Figuras 2 e 3), principalmente o genótipo Amarelinho, que apresentou aumento nas características de crescimento devido ao ataque de Meloidogyne incognita. Esse aumento na população do nematóide é consistente, pois esses patógenos se multiplicam em escala logarítmica apresentando assim considerável potencial de reprodução ( TAYLOR ; SASSER, 1978 ). Os autores afirmam que alguns fatores como os ambientais, características de solo e cultivo, percentual de ovos viáveis, entre outros, influenciam a reprodução dos nematóides, sendo que 
a quantidade de nematóides com a qual a planta foi inoculada é crucial.

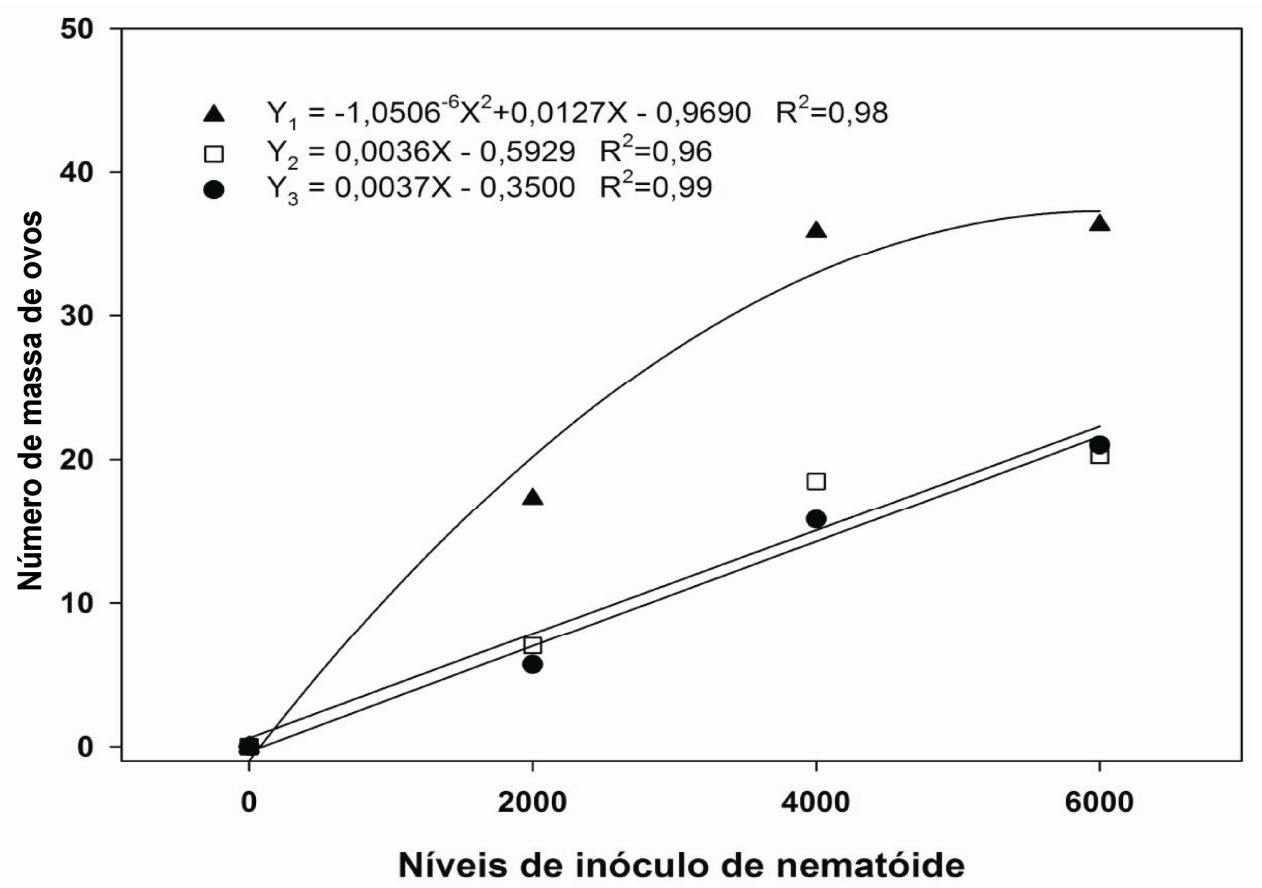

Figura 2. Número de massas de ovos (NMO) nos feijoeiro Amarelinho ( $\left.\mathrm{Y}_{1}\right)$, Córrego Alto $\left(\mathrm{Y}_{2}\right)$ e Pérola $\left(\mathrm{Y}_{3}\right)$ parasitados por quatro níveis iniciais de inóculo de Meloidogyn incognita $(0 ; 2.000 ; 4.000$ ou 6.000 ovos + juvenis de segundo estádio, J2/planta). Alegre-ES. 05 de maio de 2009.

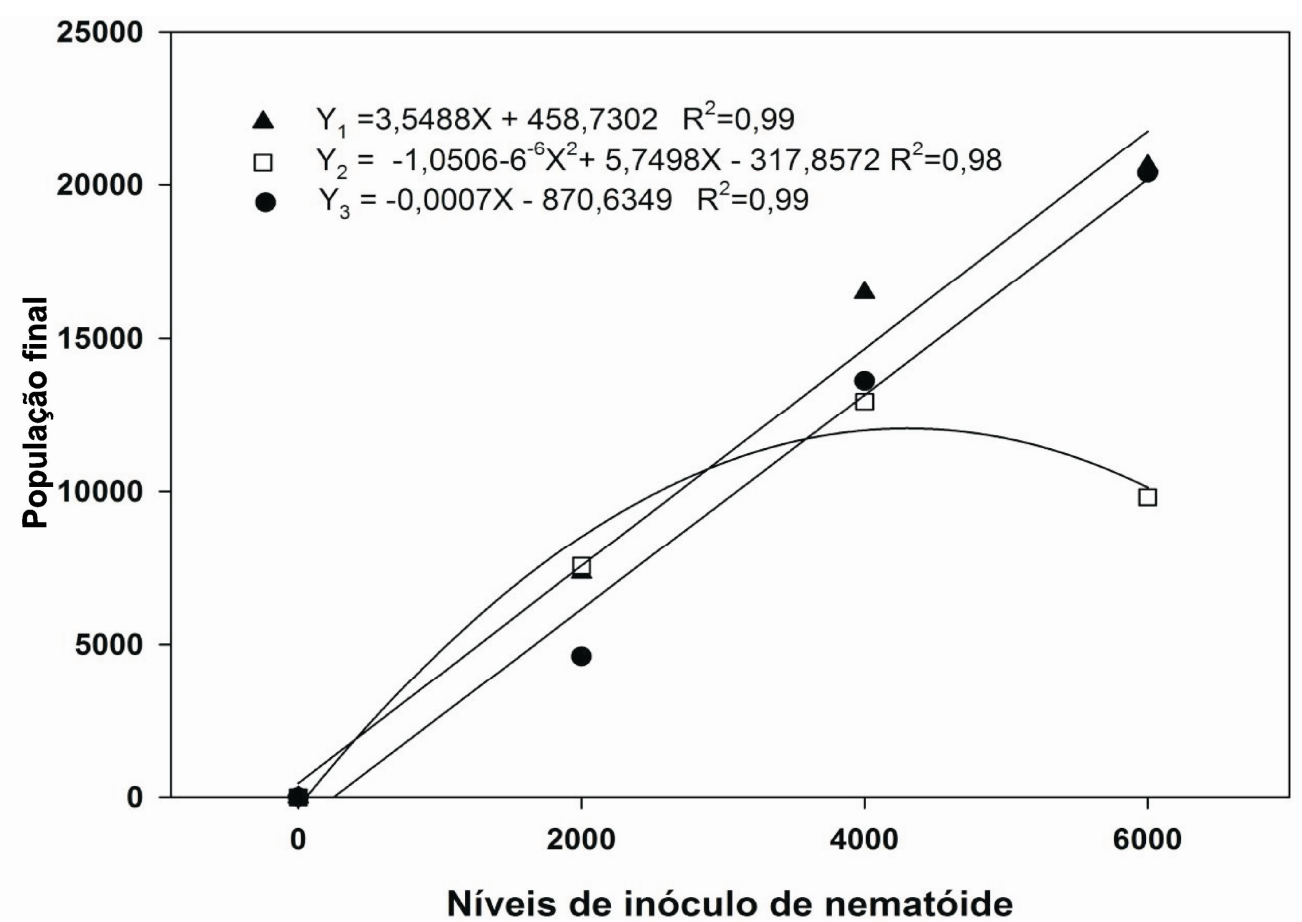

Figura 3. População final (PF) de $M$. incognita considerando quatro níveis iniciais de inóculo do nematóide Meloidogyne incógnita (0; 2.000; 4.000 ou 6.000 ovos + juvenis de segundo estádio, J2/planta) nos feijoeiro Amarelinho $\left(\mathrm{Y}_{1}\right)$, Córrego Alto $\left(\mathrm{Y}_{2}\right)$ e Pérola $\left(\mathrm{Y}_{3}\right)$. Alegre-ES. 05 de maio de 2009.

Foram observados maiores MSF e MST no genótipo Amarelinho à medida que foram aumentados os níveis de inóculo do nematóide (Figura 4). Esse resultado, aparentemente 
contraditório, pode ser explicado pelo fato de ter ocorrido um provável estresse decorrente do parasitismo dos nematóides sobre as plantas, o que culminou com um estímulo ao crescimento. Abrão e Mazzafera (2001) avaliaram o crescimento das cultivares Acala (suscetível) e IAC-20 (tolerante) de algodão (Gossypium hirsutum) inoculadas com diferentes níveis de inóculo (0, 500 e 5.000 ovos.planta $\left.{ }^{-1}\right)$ de Meloidogyne incognita raça 3 e observaram que plantas inoculadas com 500 ovos ficaram mais altas em relação à testemunha. Os autores atribuem esse tipo de resposta ao estresse que as plantas sofreram ao serem parasitadas pelos nematóides. Vale ressaltar que aumentos da MSF e MST não implicam necessariamente em maior produtividade, pois as plantas apresentaram estiolamento a medida que aumentou o inóculo inicial de nematóide.

Assim, apesar das plantas apresentarem aumento nas características de crescimento, pode-se afirmar que o parasitismo dos nematóides sobre estas é danoso, pois, quando parasitadas por Meloidogyne spp., as culturas de um modo geral apresentam o sistema radicular com alterações fisiológicas e anatômicas, o que implica em redução na absorção de água e nutrientes (ZIMMERMAN ; MCDONOUGH, 1978; HUSSEY, 1985; CAMPOS, 2000). Nesse experimento nem todos os genótipos chegaram ao estágio de produção no momento programado para a coleta do experimento, o que não permitiu a comparação da produtividade das cultivares em função dos crescentes níveis de inóculo do nematoide, precisando de novos trabalhos que mostrem efeito do ataque de Meloidogyne incognita sobre a produção do feifoeiro.

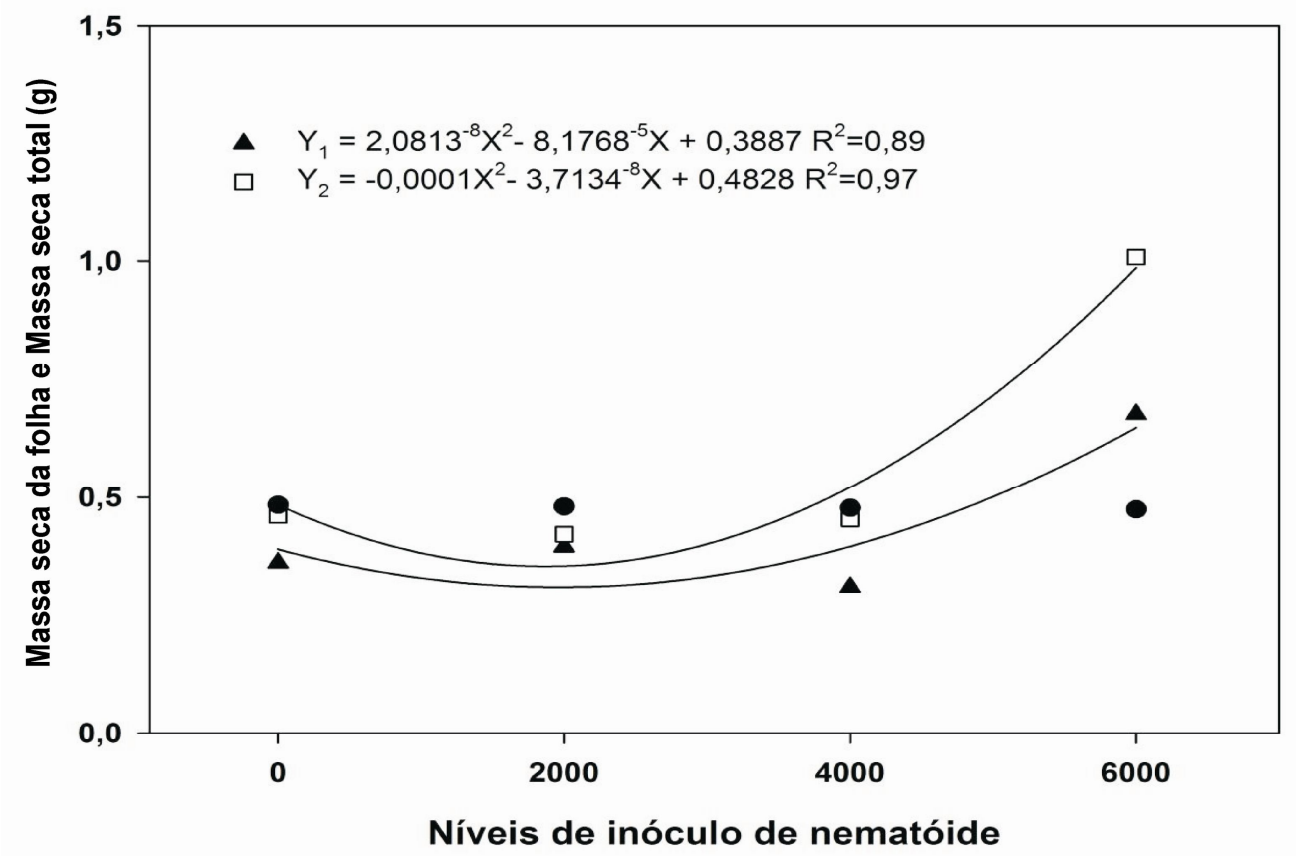

Figura 4. Matéria seca da folha $\left(\mathrm{MSF}, \mathrm{Y}_{1}\right)$ e matéria seca total (MST, $\mathrm{Y}_{2}$ ) do feijoeiro Amarelinho parasitados por quatro níveis iniciais de inóculo de Meloidogyne incognita (0; 2.000; 4.000 ou 6.000 ovos + juvenis de segundo estádio (J2)/planta). Alegre-ES. 05 de maio de 2009. 
O genótipo Pérola, suscetível à Meloidogyne spp., não teve suas características de crescimento reduzida de forma significativa. Esse resultado se harmoniza com o de Simão et al. (2005), que ao trabalharem com dois genótipos de feijão, sendo uma delas a Pérola, verificou que ambas foram susceptíveis aos nematóides, mesmo quando estas plantas tiveram a mesma pressão de infestação. Apesar disso, no presente trabalho não foi observada diferença significativa de desenvolvimento entre as plantas inoculadas e a testemunha. Já Pedrosa et al. (2000), trabalhando com 162 variedades de feijoeiro, obtiveram comportamento diferenciado quanto à resistência à $M$. javanica.

A suscetibilidade de genótipos de feijoeiro ao parasitismo de nematoides do gênero Meloigogyne também foi observada por diferentes autores. Silva e Campos (2002) avaliaram a reação de 39 linhagens de feijoeiro e observaram que todos os materiais avaliados foram bons hospedeiros dos nematóides. Os autores observaram também que houve diferença de parasitismo entre os nematóides, mostrando que um mesmo genótipo de feijoeiro pode reagir de forma diferenciada frente às diferentes espécies de nematoides.

\section{CONCLUSÃO}

Todos os genótipos foram susceptíveis ao Meloidogyne incógnita, não devendo nenhum deles serem utilizados em programa de melhoramento genético que busque resistência a esta espécie de nematoide.

Os genótipos não apresentaram diminuição das suas características de crescimento, porém com o aumento dos níveis de nematoide houve um estiolamento acentuado, que poderá influenciar na produção do feijoeiro.

\section{REFERÊNCIAS}

ABRÃO, M.M.; MAZZAFERA, P. Efeitos do nível de inóculo de Meloidogyne incognita em algodoeiro. Bragantia, v.60, p.19-26, 2001.

AGUDELO, F.V. Nematodes. In: SCHWARTZ, H.F.; GALVEZ, G.E. Bean production problems: disease insect, soil and climatic constraints of Phaseolus vulgaris. CIAT. 1980. p.315-326.

BASSANEZI, R.B. Interações entre mosaico-em-desenho do feijoeiro e duas doenças fúngicas, ferrugem e mancha angular em plantas de feijoeiro. 1995. 127f. Dissertação (Mestrado) - Escola Superior de Agricultura "Luiz de Queiroz", Piracicaba.

BONETI, J.I.S.; FERRAZ, S. Modificações do método de Hussey ; Barker para extração de ovos de Meloidogyne exigua em raízes de cafeeiro. Fitopatologia Brasileira, v.6, p.533, 1981. 
CAMPOS, V.P. Doenças causadas por nematóides em tomate. In: ZAMBOLIM, L.; VALE, F.X.R.; COSTA, H. Controle de doenças de plantas - Hortaliças. Viçosa: UFV, 2000. p. 801-842.

CAMPOS, V.P. Manejo de doenças causadas por fitonematóides. Curso de pós-graduação à distância: Manejo de doenças de plantas. UFLA. 1999. 120 p.

CARNEIRO, R.G. et al. Estudo de mecanismo de resistência a Meloidogyne incognita raça 3 em variedades de feijoeiro. Nematologia Brasileira, v.16, p.41-52, 1992.

CRUZ, C.M. Programa GENES estatística experimental e matrizes. UFV. 2006. 285 p.

FREIRE, F.C.O.; FERRAZ, S. Nematóides associados ao feijoeiro, na Zona da Mata, Minas Gerais, e efeitos do parasitismo de Meloidogyne incognita e M. javanica sobre o cultivar "Rico 23". Ceres, v.24, p.141-149, 1977.

HUSSEY, R.S.; BARKER, K.R. A comparison of methods of collecting inocula of Meloidogyne spp. including a new technique. Plant Disease Reporter, v.57, p.1025-1028, 1973.

HUSSEY, R.S. Host-parasite relationships and associated physiological changes. In: SASSER, J.N.; CARTER, C.C. (Eds.). An advanced treatise on Meloidogyne: biology and control. North Carolina: Raleigh, 1985. p.143-153.

JESUS JÚNIOR, W.C. et al. Tomada de decisão no manejo de doenças de plantas. In: VALE, F.X.R.; JESUS JÚNIOR, W.C.; ZAMBOLIM, L Epidemiologia aplicada ao manejo de doenças de plantas. Belo Horizonte: Perfil, 2004. p.468-475.

MICHEREFF, S. Quantificação de danos causados por fitopatógenos habitantes do solo. In: VALE, F.X.R. Workshop de epidemiologia de doenças de plantas - Quantificação de perdas no manejo de doenças de plantas, 1, 2004, Viçosa. Anais... São Paulo, 2004. p. 95-105.

MOURA, R.M.; REGIS, E.M.O. Reações de feijoeiro comum (Phaseolus vulgaris) em relação ao parasitismo de Meloidogyne javanica e $M$. incognita (Nematoda: Heteroderidae).

Nematologia Brasileira, v.11, p.215-225, 1987.

MOURA, R.M.; MOURA, A.M. de. Comportamentos de genótipos de Phaseolus vulgaris em relação aos nematoides Meloidogyne incognita raça 1 a $M$. javanica. Nematologia Brasileira, v.18, p.50-56, 1994.

PEDROSA, E.M.R.; MOURA, R.M.; SILVA, E.G. Respostas de genótipos de Phaseolus vulgaris à meloidoginose e alguns mecanismos envolvidos na reação. Fitopatologia

Brasileira, v.25, p.190-196, 2000.

PEIXOTO, J.R. Melhoramento do pimentão (Capsicum annuum L.) visando à resistência aos nematoides do gênero Meloidogyne spp. 1995. 105f. Tese (Doutorado) - Universidade Federal de Lavras.

PERRE, J.; SANTOS, M.A. Reação de cultivares de feijoeiro comum aos fitonematóides de importância primária. In: CONGRESSO BRASILEIRO DE FITOPATOLOGIA, 12, 2002, Uberlândia. Anais... Uberlândia, Sociedade Brasileira de Fitopatologia, 2002. p. 192. 
PREZOTTI, L.C.et al. Manual de recomendação de calagem e adubação para o Estado do Espírito Santo, $5^{\circ}$ aproximação. SEEA/INCAPER/CEDAGRO. 2007. 305p.

ROBERTS, P.A. Current status of the availability, development, and use of host plant resistance to nematodes. Journal of Nematology, v.24, p.213-217, 1992.

SILVA, J.V.; CAMPOS, H.D. Reação de cultivares de feijão a nematoides de galhas. In: CONGRESSO NACIONAL DE PESQUISA DE FEIJÃO, 7, 2002, Viçosa. Anais... Viçosa, Universidade Federal de Viçosa, 2002. p.102.

SIMÃO, G.et al. Reação de cultivares e linhagens de feijoeiro em relação a Meloidogyne javanica e Fusarium oxysporum f. sp. Phaseoli. Ciência rural, v.40, p.1003-1008, 2010.

SIMÃO, G.et al. Comportamento de duas cultivares de feijoeiro em ralação a Meloidogyne incógnita. Ciência Rural, v.2, p.266-270, 2005.

TAYLOR, A.L.; SASSER, J.N. Biology, identification and control of root-knot nematodes (Meloidogyne spp.). Raleigh. 1978. 111p.

VIEIRA, C. Doenças e pragas do feijoeiro. UFV. 1993. 231 p.

WALBER, R. et al. Avaliação de acessos de feijoeiro em relação aos nematóides das galhas. In: CONGRESSO BRASILEIRO DE FITOPATOLOGIA, 36, 2003, Uberlândia. Anais... Brasília, Sociedade Brasileira de Fitopatologia, 2003. p.293-294.

YOKOYAMA, L.P. Cultivo do feijoeiro comum: sistemas de produção, 2. Disponível em: http://sistemasdeproducao.cnptia.embrapa.br/FontesHTML/Feijao/CultivodoFeijoeiro/importa ncia.htm. Acesso em: 29 dez. 2009.

ZIMMERMAN, M.H.; MCDONOUGH, J. (1978) Disfunction in the flow of food. In: HORSFALL, J.G.; COWLING, E.B. (Ed.) Plant disease: an advanced treatise. New York, Academic Press. p.117-140. 